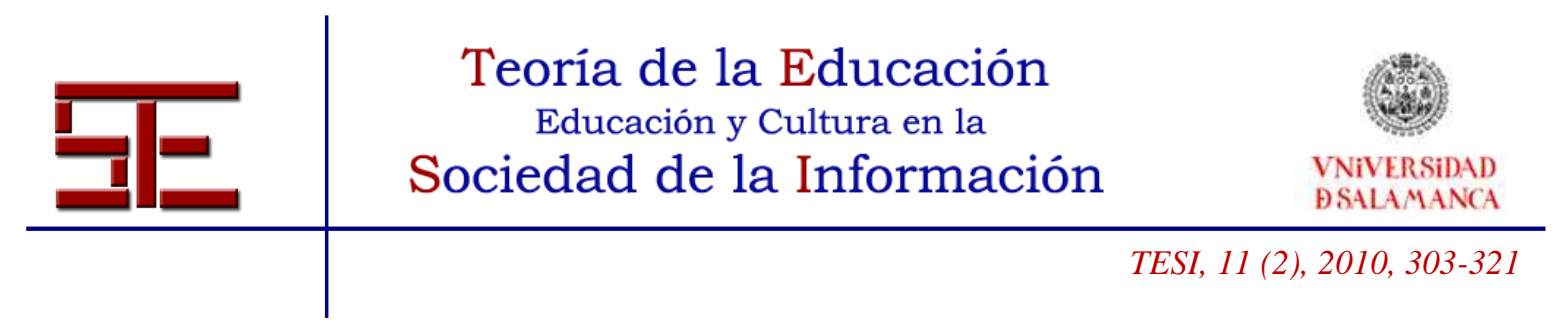

\title{
ALFABETIZACIÓN MEDIÁTICA. LA EDUCACIÓN EN LOS MEDIOS DE COMUNICACIÓN: CINE FORMATIVO Y TELEVISIÓN EDUCATIVA
}

\section{Resumen:}

Se plantea en estos momentos un debate abierto sobre el uso de las denominadas TIC en el aula. No debemos olvidar el gran valor que en todas ellas tiene la imagen. Quizá muchos consideren que el cine y la televisión ya no son nuevas tecnologías, pero, sin embargo, la mayoría de estas nuevas tecnologías -hoy calificadas como nuevas pero probablemente consideradas obsoletas en poco tiempo- se basan en el uso de la imagen. Deberíamos, por tanto, formar a nuestros alumnos en el uso consciente y eficaz de ésta. Deberíamos saber aprovechar su potencial en el aula, ya que es un recurso del que podemos disponer con relativa facilidad y que sigue siendo, la imagen y por extensión su uso en los medios de comunicación, uno de los más importantes agentes socializadores. Del buen uso que nuestros alumnos hagan de la imagen y de los medios de comunicación, dos de los instrumentos de mediación más importantes, depende, en gran parte, su socialización y educación.

Palabras clave:Alfabetización mediática, medios de comunicación, cine formativo, televisión educativa, enseñanza, TIC.

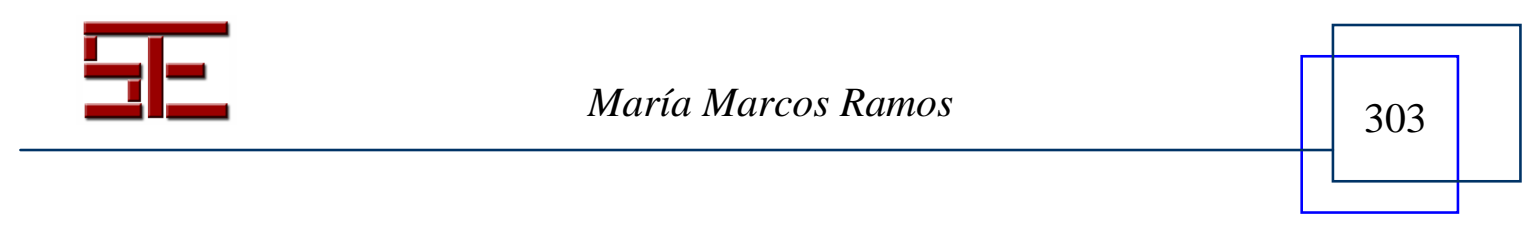




\section{MEDIA LITERACY. THE EDUCATION IN THE MASS MEDIA: FORMATIVE CINEMA AND EDUCATIONAL TELEVISION}

\section{Abstract:}

A debate opened on the use in these moments of named TIC in the classroom. We must not forget the great value that in all of them has the image. Probably many people think that the cinema and the television already are not new technologies, but without seizure the majority of these new technologies - today qualified like new but they will be considered to be obsolete in a little time - they are based on the use of the image. We should form, therefore, our pupils in the conscious and effective use of this one. We should be able to take advantage of his potential in the classroom since it is a resource which we can have with relative facility and which continues being, the image and for extension his use in the mass media, one of the most important agents of socialization. Of the good use that our pupils do of the image and of the mass media, two of the more important instruments of mediation, his socialization and education depends, largely.

Key words: Media literacy, mass media, formative cinema, educational televisión, education, TIC.

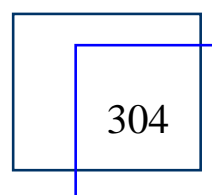




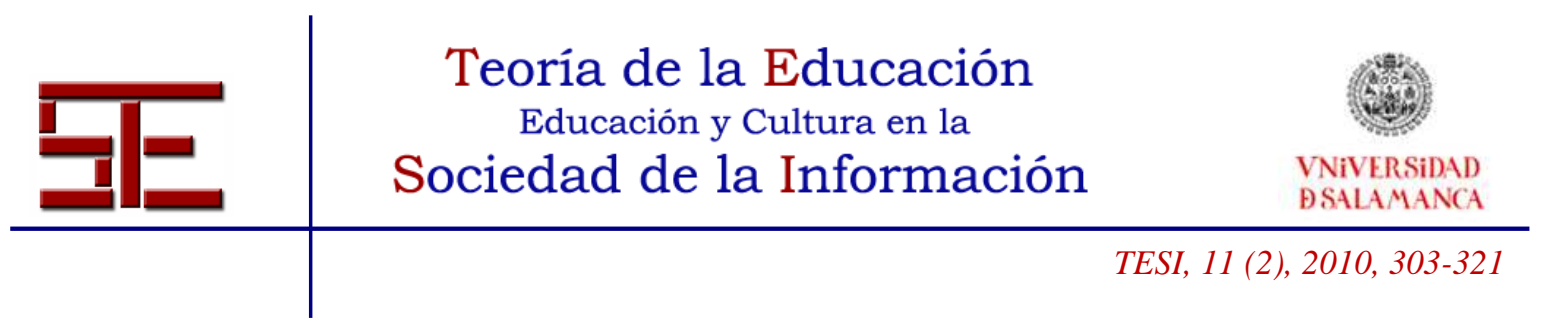

\title{
ALFABETIZACIÓN MEDIÁTICA. LA EDUCACIÓN EN LOS MEDIOS DE COMUNICACIÓN: CINE FORMATIVO Y TELEVISIÓN EDUCATIVA
}

Fecha de recepción: 19/09/2009; fecha de aceptación: 15/05/2010; fecha de publicación: 01/07/2010

\author{
María Marcos Ramos \\ mariamarcos@usal.es \\ Universidad de Salamanca.
}

\section{1.- INTRODUCCIÓN}

No cabe duda de que a estas alturas se hace necesario, ya que vivimos rodeamos de información y de medios de comunicación que nos la ofrecen, diseñar unas políticas educativas, tanto dentro de la escuela como en el entorno que nos rodea, que se ocupen de la llamada alfabetización digital. En la escuela se nos enseña a leer y a escribir, pero esta alfabetización -denominada analógica- no se limita sólo a que sepamos diferenciar una letra de otra, a que sepamos cómo suena si juntamos una "c" con una "a": esta alfabetización va más allá. Olson $(1995,75)$ ha señalado que "la escritura no es una mera trascripción del habla, sino que más bien proporciona un modelo conceptual para el habla (...); las escrituras como sistemas simbólicos emergentes en sí mismos que intentan ajustarse dificultosamente y que interactúan con el sistema simbólico del habla. Y al hacerlo, al aprender a leer y escribir, aprendemos uno o unos sistemas simbólicos distintos del habla y que a la vez nos sirven como una especie de modelo de contraste para comprender ésta, para pensar en el lenguaje oral". Así, al igual que en la escuela se enseña a leer y a escribir, se hace necesaria la incorporación dentro del currículum de la alfabetización audiovisual o mediática:

Deberá contemplarse la alfabetización mediática no sólo en relación con los aspectos de los medios y los lenguajes audiovisuales, sino atendiendo también a los grandes procesos de desarrollo mental: atención, educación perceptiva (pictorial consciousness), estructuras de representación, factualidad y realismo social, narrativa, drama, etcétera) (Del Río, Álvarez y Del Río, 2004).

La escuela, al igual que las políticas educativas, parece que siempre llega tarde y es reticente a incluir cambios en sus currículums, abriendo cada vez más la brecha existente entre docentes y alumnos. Éstos, más tecnológicos y acostumbrados a los nuevos me-

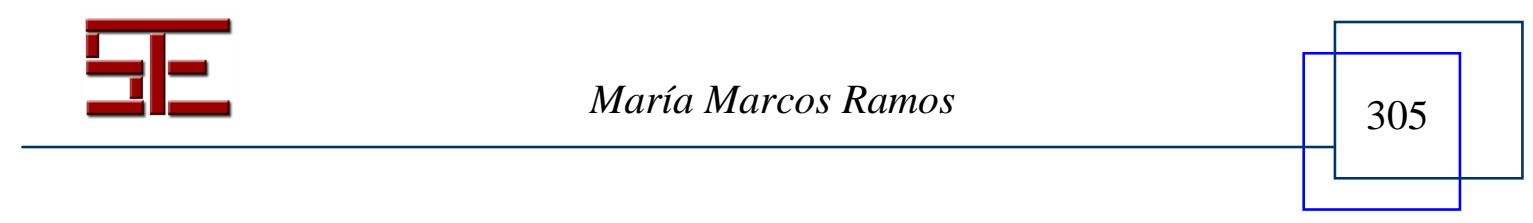




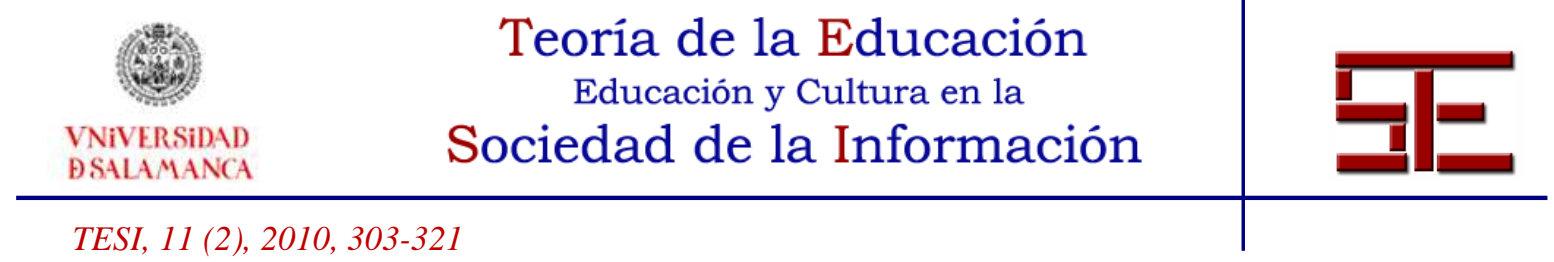

dios de comunicación, no entienden por qué no se emplean las nuevas tecnologías -las denominadas TIC - en la práctica educativa. Los docentes, por otro lado, no se sienten respaldados por parte de las instituciones para su utilización; muchos de ellos no han recibido formación sobre estas materias y otros son de la "vieja escuela" y son reticentes al uso de las mismas.

Algunos profesores creen que la utilización de las TIC o de la televisión ${ }^{1}$ en el aula no es más que una diversión más para los alumnos, que así no van a estudiar y que no es natural. Pero, ¿qué hay en el aula que sea natural? El aula no es más que un mundo representacional limitado donde se imparte una cultura mediada. La inclusión de estas nuevas herramientas no es más que una reubicación de todos los elementos presentes en el aula para su utilización en la práctica docente y en el proceso de aprendizaje.

Al igual que pasa con la lectura, las matemáticas u otras disciplinas, el consumo mediático -ver televisión, películas, leer cómics, periódicos, revistas, navegar por Internet...no genera por sí solo competencias mediáticas, salvo de bajo nivel. Las competencias alfabéticas de alto nivel se benefician de una enseñanza articulada entre alfabetización verbal y alfabetización mediática, audiovisual, digital y otras alfabetizaciones.

Para bien o para mal, los medios de comunicación son uno de los grandes educadores, enculturizadores, de los niños y adolescentes -incluso de los adultos-. Por eso, debemos hacer que sean para bien, que se utilicen de manera constructiva. Dos de las múltiples acciones que pueden desarrollarse en la escuela para lograr una alfabetización digital serían la utilización del cine formativo y la educación audiovisual mediante el uso de programas educativos ${ }^{2}$. En los países desarrollados se ha generado una doble influencia en los diseños educativos y en los modelos curriculares: la inclusión sobre contenidos de alfabetización mediática o audiovisual y la reorganización del currículum educativo para articularse conjuntamente con los procesos educativos y de desarrollo del contexto cultural y mediático.

\section{2.- LA IMAGEN EN EL AULA: CINE FORMATIVO Y EDUCACIÓN MEDIÁ- TICA}

Saturnino de la Torre $(1997,17)$ define el cine formativo "como la emisión y recepción intencional de películas portadoras de valores culturales, humanos, técnico-científicos o artísticos, con la finalidad de mejorar el conocimiento, las estrategias o las actitudes y opiniones de los espectadores". De la Torre añade que tres son las características que deben poseer las películas que se enmarcarían en el denominado cine formativo:

En primer lugar, han de poseer determinados valores o méritos humanos; en segundo lugar estar codificados de forma que sean interpretables y en tercer lugar que exista una intención de utilizar dicho medio como recurso formativo, es decir, con voluntad de producir algún tipo de aprendizaje,

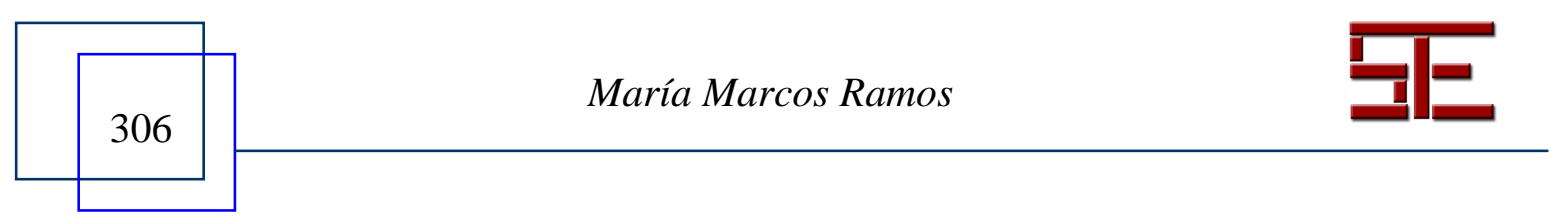




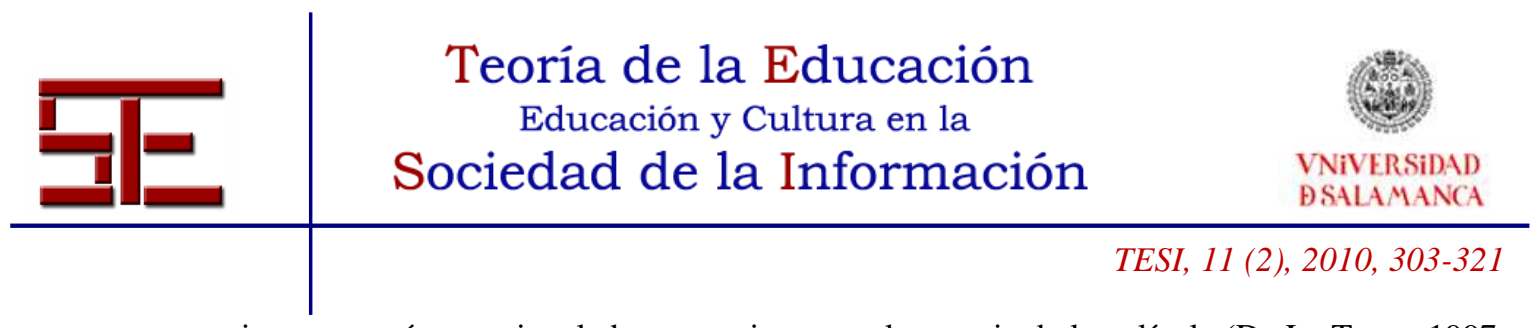

que no tiene por qué estar vinculado necesariamente al mensaje de la película (De La Torre, 1997, 17).

Así, casi cualquier película podría ser utilizada y contextualizada bajo la etiqueta de cine formativo. Es tan importante que la película contenga valores como que el profesor o mediador sepa utilizar los elementos que toda película contiene, esto es, una película bélica, evidentemente cargada de imágenes y comportamientos violentos, puede servirnos para trabajar actitudes pacifistas.

Para el marco de este artículo sería cine formativo aquel cine que nos sirva para que el docente trabaje con los alumnos ciertas actitudes, valores y comportamientos independientemente de que posea ciertos valores éticos.

Para un docente una película puede tener carácter formativo y para otro no tenerlo ya que "un sujeto puede aceptar como formativos ciertos filmes, de manera totalmente incomprensible para otro. Más aún, para uno puede ser interesante la información que se ofrece, para otro la formación que se recibe, y para un tercero la formación e información que puede captar" (Tort, 1997, 31).

En esta misma línea se pronuncia Tornel $(2007,275)$ al señalar que cualquier película puede ser empleada desde un punto de vista formativo ya que transmite los contenidos adecuados, permitiendo la interiorización y puesta en marcha de tales contenidos, conjuntamente con sus respectivos valores y conductas asociadas.

El valor formativo que pueda tener una película será aquel que el docente le dé ya que al adoptar un papel de "mediador formativo entre la película y el alumno" (De la Torre, 1997, 18) y al dotarla de intencionalidad didáctica, tal y como indica Avelino Escudero (1997, 37) "todos los medios de comunicación se convierten en servicio educativo cuando la educación los utiliza con fines instructivos y formativos o cuando, a la inversa, dichos medios realizan una función educadora en virtud de sus contenidos y programas". En este sentido, no es tanto el valor ético que tenga el filme -o imagen, programa o cualquier contenido audiovisual- sino más bien el valor añadido que le ofrece el docente al trabajar ciertos aspectos de la imagen con los alumnos.

Resulta fundamental el papel que desempeña el docente, formador, experto o coordinador, es decir, el mediador entre la imagen y los alumnos, ya que de él depende el éxito o fracaso de la actividad. El docente "es el principal transformador de las escenas o relato fílmico en códigos de aprendizaje significativo. Él ayuda a descodificar, desde planteamientos pedagógicos, las acciones, situaciones, personajes, etc. ajenos posiblemente a dicha consideración" (De la Torre, 1997, 18). Se necesita, por tanto, profesorado formado en el área de la imagen, con capacidad de análisis audiovisual y con vastos conocimientos del medio, ya que hasta que no se forme al profesorado en estos medios cual-

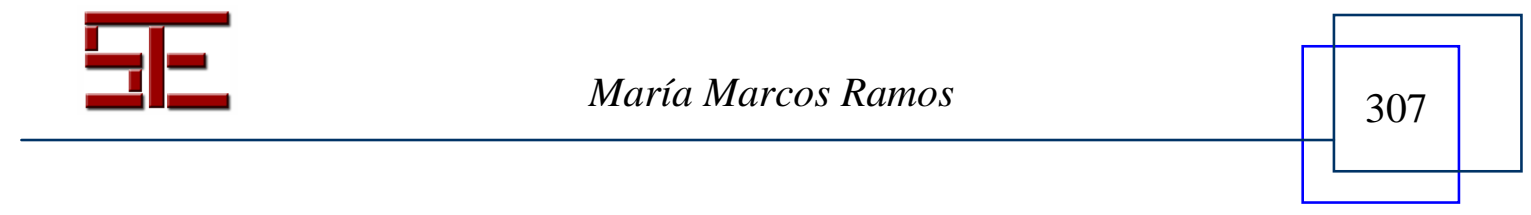




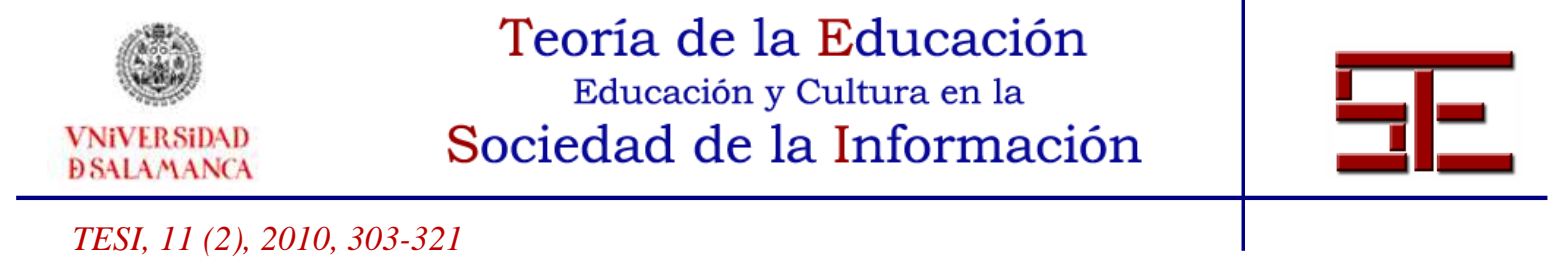

quier política de introducción de los mismos en el contexto escolar puede ser baldía (Cabero, 1992).

Tal y como han señalado Ambrós y Breu sobre este tema:

Desde sus orígenes, el cine ha sido un elemento transmisor de conceptos, valores y pautas de conducta. Tiene una innegable influencia en los valores de la sociedad (...) también de contravalores, de creencias y comportamientos (...) El cine merece ser un espacio formativo (...) Es necesario aprovechar su potencialidad formativa (Ambrós y Breu, 2007, 26-28).

Es, por tanto, el cine o la imagen un recurso didáctico imprescindible para enriquecer en los alumnos competencias de comunicación, de reflexión, de diálogo permanente y, sobre todo, de espíritu crítico ya que "el cine como estrategia didáctica (...) puede servir de puente entre los contenidos que se están intentando discutir, y cómo se viven en la realidad" (Campo-Redondo, 2006, 16).

La escuela se percibe como el escenario ideal para la aplicación del cine formativo o del uso didáctico de la imagen como recurso formativo. Tradicionalmente, la educación ha estado ligada a impartir conocimientos de manera unidireccional, mediante una clase magistral en la que el docente sólo se apoyaba, como recurso didáctico, en sus conocimientos, la pizarra y algunas fotocopias, relegando el uso de la imagen como complemento formativo a una mera anécdota. Sin embargo, hoy en día se integran nuevas estrategias educativas entre las que nos encontramos con "la incorporación del lenguaje audiovisual cinematográfico como complemento de la enseñanza" (Campo-Redondo, 2006, 14). Es, por tanto, imprescindible en la era de la imagen y de la comunicación "contar con personas que estén preparadas para enseñar a leer las imágenes que vehiculan las historias que se explican, que sepan hacer reflexionar sobre éstas, y que sepan promover, frente a ellas, una verdadera autonomía crítica" (Tort, 1997, 32).

Han sido diversas las actitudes adoptadas por los docentes a la hora de utilizar la imagen audiovisual en las aulas ${ }^{3}$. En este sentido Alonso, Matilla y Vázquez (1995, 204-207) señalan tres posturas diferentes. Por un lado, la denominada respuesta cero sería la de aquellos docentes que piensan que la imagen audiovisual no tiene ninguna virtualidad educativa. Los docentes que sienten cierta indiferencia hacia el medio, que no se pronuncian ni a favor ni en contra tendrían una respuesta uno. La respuesta dos sería la de aquellos docentes que consideran necesario un cambio en el sistema educativo derivado del cambio social y cultural de la sociedad.

La televisión puede desempañar diferentes funciones en el aula (López, 1998, 68) según el lugar y peso que le dé el profesor en su utilización. Puede tener una función complementaria cuando el maestro carece de ciertos recursos que apoyen su explicación llegando a tener una función suplementaria cuando es utilizada como guía para el aprendi-

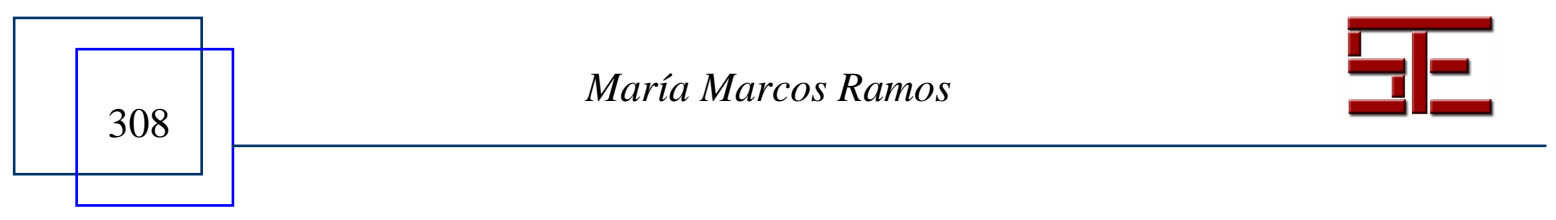




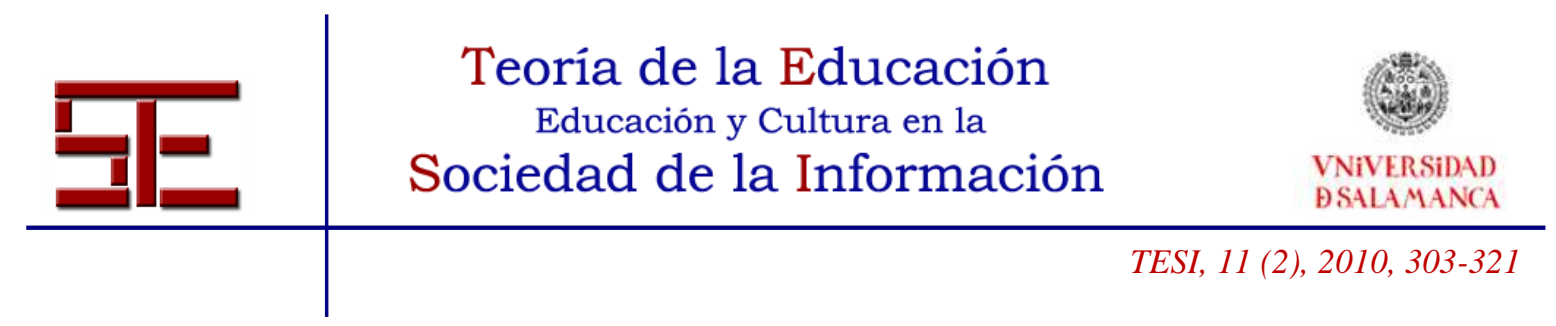

zaje sustituyendo la clase magistral del educador. Tendría una función extensiva cuando se emplea para desarrollar un plan general de educación especializada. La televisión tendría una función de desarrollo cuando se ofrecen unos conocimientos básicos que sitúen al ciudadano en el mundo.

El uso de la imagen -cine, televisión, anuncios gráficos, etc.- tiene un gran poder motivador y de atracción. En el aula actual uno de los problemas más importantes a los que se enfrentan los profesores es la falta de motivación de los alumnos. Se hace, por tanto, necesaria la búsqueda de nuevos recursos didácticos que motiven a los alumnos y, si la imagen reúne estas características, no tiene sentido rechazar el uso si funciona y es necesario. El uso de la imagen como estrategia didáctica consolida conocimientos, genera actitudes, despierta el sentido crítico y promueve un aprendizaje integrado y multisensorial con el que poder trabajar valores educativos, sociales, de integración, de tolerancia... El cine en el aula ayuda a fomentar (Ambrós y Breu, 2007) la imaginación y el lenguaje; a promover el gusto por la pregunta y la crítica, el descubrir y la interpretación; a ampliar las capacidades expositivas y de razonamiento; a trabajar diversos aspectos ligados al mundo propio del alumnado, como es la imagen audiovisual; a poner en funcionamiento la memoria, el entretenimiento y la sensibilidad para captar el significado más profundo de la realidad, y hace que se adopten posturas, formando opiniones, interiorizando una historia y elaborando conclusiones.

Tan fundamental es que se enseñe a leer en el centro escolar como que se enseñe a ver en un mundo cada vez más visual. Se trata de "educar para el uso de la televisión: formar espectadores conscientes, críticos y activos, capaces de programar su propio consumo y de realizar un uso eficiente de la televisión" (Pérez, 1994, 27). Ésta ha sido una de las vías que más se han impulsado por parte de las instituciones para fomentar una educación audiovisual: educar para el uso de la televisión. Chalvon, Corset y Souchon (1982, 103) señalan que es:

Es la escuela donde se debería sobre todo aprender a ver la televisión. Y en primer lugar, a analizar sus códigos, ya que se trata de reconsiderar todo lo que las emisiones de televisión dan como natural y evidente, lo "inverosímil" en que construyen sus sistemas de signos y que ellos contribuyen de esta forma a difundir y a imponer. La finalidad es llegar a una lectura consciente de las imágenes, donde lo implícito esté explícito.

Conscientes de esta carencia desde las instituciones educativas se han tomado medidas para resolver este "analfabetismo icónico" "Son dos las vías que se han llevado a cabo: enseñar a leer la imagen -a ver la televisión- y enseñar a utilizar la imagen -a conocer los códigos internos de la imagen y del funcionamiento de la televisión ${ }^{5}$-. Algunos expertos han denominado a estas dos posturas educar en la televisión y educar con la televisión. Según Joan Ferrés (1994, 121-122):

Una adecuada integración de la televisión en el aula supone atender dos dimensiones formativas: educar en la televisión y educar con la televisión. Educar en la televisión significa convertir el me-

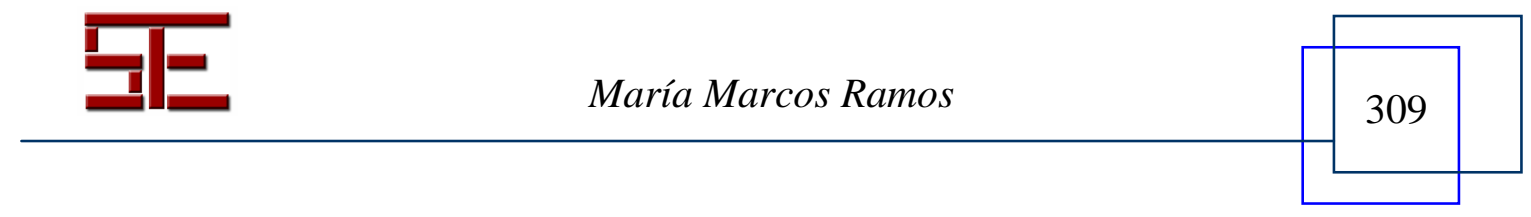




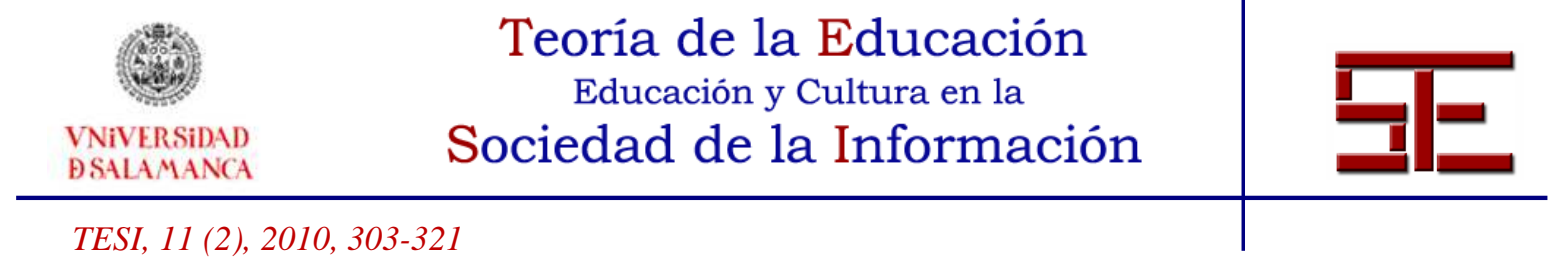

dio en materia u objeto de estudio. Supone educar en el lenguaje audiovisual, enseñar los mecanismos técnicos y económicos de funcionamiento del medio, ofrecer pautas y recursos para el análisis crítico de los programas (...) En definitiva, realizar una aproximación al medio desde todas las perspectivas: técnica, expresiva, ideológica, social, económica, ética, cultural (...) Educar en la televisión. Pero también educar con la televisión. Incorporarla al aula, en todas las áreas y niveles de la enseñanza, no para incrementar aún más su consumo, sino para optimizar el proceso de enseñanza-aprendizaje.

Educar en la televisión tendría como objeto estudiar la televisión como medio de comunicación, conocer cómo se trabaja en el medio, por qué se emiten unas imágenes y no otras, esto es, "conocer el sistema televisivo, aprendiendo sus códigos y lenguajes, analizando sus contenidos y valores, conociendo sus efectos e influencias" (Sánchez Noriega, 1997, 450). Todos estos contenidos se han recogido en una asignatura optativa denominada Comunicación Audiovisual ${ }^{6}$.

Una vez que se interioricen estos códigos internos del medio -tanto de la televisión como de otros medios: prensa, radio, Internet...- por parte de los receptores, se habrá aprendido a leer. Este saber leer "es fruto del aprendizaje -más o menos consciente- y es una actividad mental compleja que estimula el raciocinio, la lógica y la imaginación" (Pérez Tornero, 1994, 94).

Babin y Kouloumdjian (1983, 74-75) señalan que un proceso de análisis de los mensajes debe ir acompañado de una "elaboración de sentido" y especialmente de un "distanciamiento" proporcionado, por diferentes vías: la reflexión -sobre lo sentido y vivido-; por la conceptualización - por el paso a las ideas universales-; por la apropiación -o la reconstrucción en su propio lenguaje- y, finalmente, por el juicio crítico sobre los contenidos, la forma, el lenguaje, la técnica, los procedimientos utilizados, la infraestructura comercial y económica puesta en juego...

Miguel Reyes (1993), por su parte, realiza una propuesta de educación del telespectador centrada en tres grandes áreas: la desmitificación -conocer y apreciar el medio televisivo para aproximarlo como realidad al escolar telespectador-; la alfabetización conocimiento y dominio del lenguaje de la televisión- ; y, el autoanálisis -toma de conciencia de las necesidades, motivaciones y reacciones que produce la televisión en el telespectador -

Pérez Tornero (1994, 153-159) establece una serie de propuestas para educar a ver la televisión. Estas propuestas las divide entre situaciones críticas y operaciones críticas. Dentro de las situaciones críticas propone:

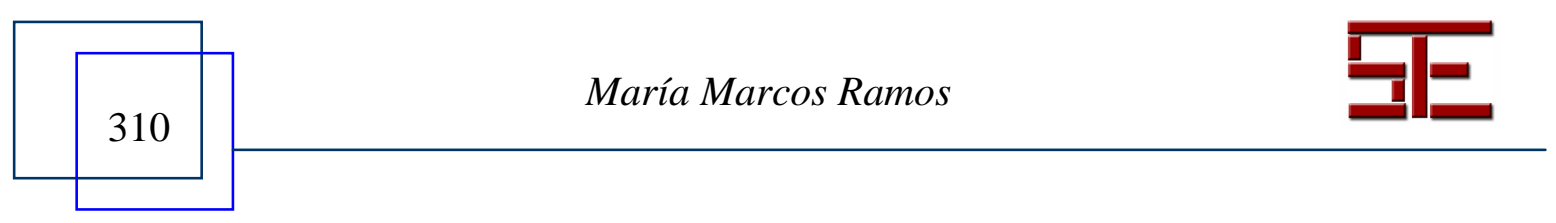




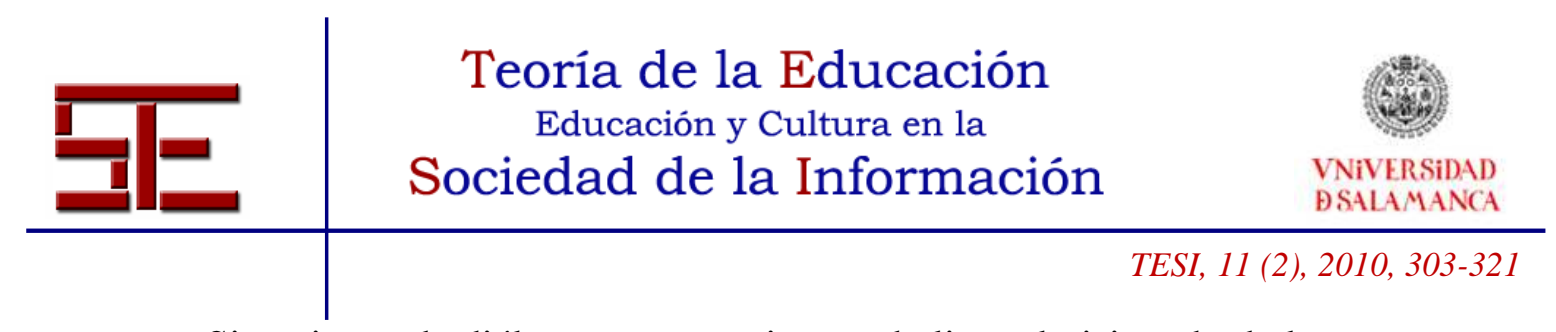

- Situaciones de diálogo, que permitan verbalizar el visionado de los programas para reinterpretarlos, para asegurarse la pluralidad de perspectivas y para distanciarse del propio lenguaje de la televisión.

- Estrategias de comparación, ya que comparar es hacer un ejercicio de intertextualidad y de confrontación, que permite situar el sentido de los textos televisivos, confrontándolos con otros, hallando semejanzas y diferencias, fórmulas de captación de la atención, estilos comunicativos...,esto es, descubriendo sus estrategias de comunicación.

Procesos creativos, de forma que se afronte imaginativamente la televisión para fantasear libremente aprovechando los elementos que nos proporciona la televisión para aportar nuestra subjetividad y nuestra creatividad.

Propuestas de confrontación de datos, puesto que hay que buscar fórmulas que permitan a los alumnos contrastar las informaciones del medio que, si bien quieren presentar como totémicas y únicas, nos obligan a desarrollar otras miradas en las que se ponga en evidencia que la televisión no es el mundo, sino un camino -entre otros-para acceder a su conocimiento.

Dinámicas de exploración formal, que faciliten el conocimiento de las estéticas de los mensajes, de sus estructuras estilísticas, de los recursos estéticos del medio, puesto que se trata de interponer entre nosotros y el lenguaje de la televisión otros lenguajes, ya no verbales, sino plásticos, musicales...

Pautas para la manipulación del medio, ya que el mensaje televisivo puede convertirse en nuestras manos en materia prima, en una oportunidad para el collage, la recreación, la resituación de todos sus elementos.

Para las operaciones críticas entendidas "como los procesos que conducen a la lectura crítica” Pérez Tornero establece las siguientes actividades (Pérez Tornero 1994, 156):

Racionalización de su uso ${ }^{7}$, ya que éste ha de adaptarse necesariamente a las necesidades, intenciones y proyectos de cada individuo. En este sentido, es trascendental que los alumnos se planteen los propósitos que nos llevan a ver televisión, a analizar la correspondencia de éstos con lo que nos ofrecen las pantallas y evaluar la posibilidad de consecución de nuestros deseos. Para ello será necesario interpelarse personal y grupalmente por los horarios, la periodicidad, la frecuencia, la gobernabilidad del consumo, el contexto en que se produce, las informaciones previas que obtenemos, la confrontación con otras posibilidades de ocio, etc.

La creación de contextos adecuados para el visionado, dotando a los espacios de suficientes medios que faciliten el análisis. Serían interesantes y necesarias la existencia de mediatecas y la potenciación de los magnetoscopios ${ }^{8}$ y videocámaras para actividades de recreación y producción.

El consumo colectivo y su verbalización, ya que el visionado aislado invita más a la hipnosis y a seguir unilateralmente el discurso del medio. Por ello, la discu-

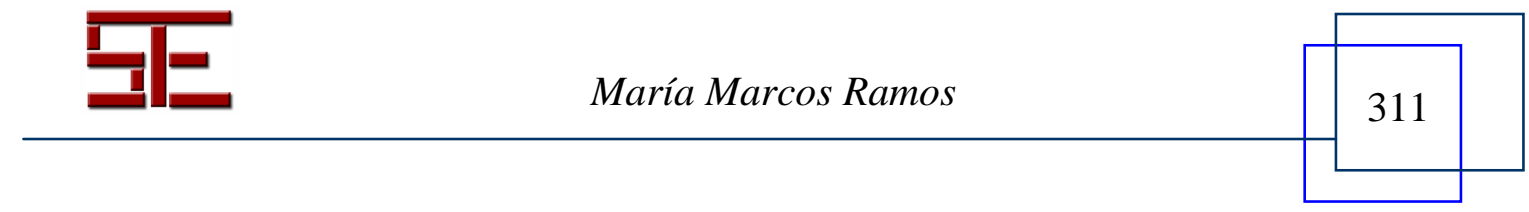




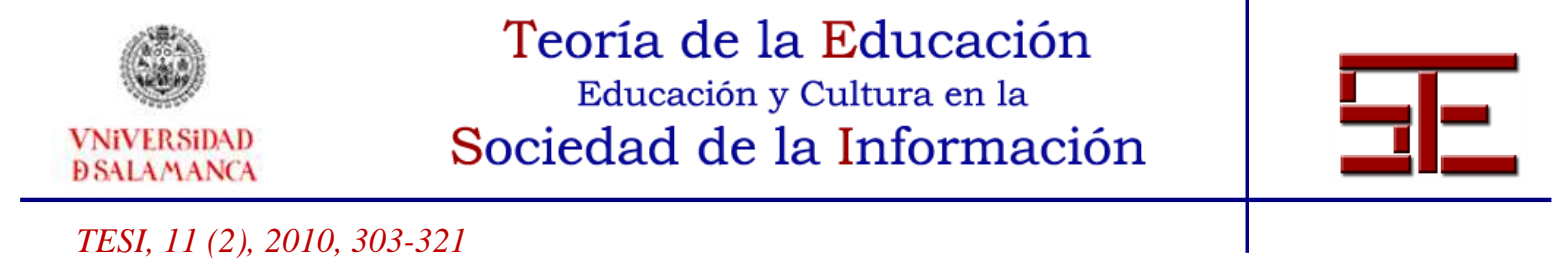

sión, la crítica colectiva, la diversidad de perspectivas que ofrece la puesta en común son estrategias básicas que hay que fomentar.

La potenciación de la dimensión pública de la televisión, ya que sólo en este caso el medio puede abandonar, al menos parcialmente, su dimensión de espectáculo y subjetividad y convertirse en un recurso de integración social.

El desarrollo de los juegos lingüísticos que permitan que la televisión pueda ser ironizada, resumida, glosada, contrastada, argumentada y contra argumentada, replicada y contradicha, afirmada y negada, provocada y estimulada... Todo ello engrandece el campo de acción del telespectador y ayuda a tomar distancia y facilitar la actividad creativa.

Desde la perspectiva de educar con la televisión se enmarca integrar la imagen en el aula, esto es, incluirla dentro del currículo siendo un elemento más. Debe ser un uso responsable y adaptado a la actividad a desarrollar, "debe estar planificado, adaptado a las actividades que se desarrollan y a las temáticas curriculares que se impartan y además acompañado de una plataforma reflexiva que sirva para aprender con el medio nuevas facetas de conocimiento, descubriendo (...) sus resortes comunicativos" (Aguaded, 1997, 38).

Han sido significativas las acciones ${ }^{9}$ que han tomado diversos Gobiernos para fomentar esta educación y formación audiovisual ${ }^{10}$. En Francia se ha llevado a cabo la campaña Jeune Téléspectateur Actif (JTA) ${ }^{11}$ para fomentar la competencia televisiva. El gobierno belga ha venido desarrollando desde el Conseil de l'Éducation aux Médias diversos programas con el fin de integrar la televisión y los medios en los currículums académicos. Si bien estos contenidos tienen un carácter transversal, sí que tienen como finalidad la de educar a futuros telespectadores responsables y críticos con los medios. En Suiza se han desarrollado los Centres d'Initiation aux Médias que han puesto en marcha diferentes experiencias en la educación de la competencia comunicativa/televisiva en los programas escolares.

El Reino Unido ha sido el país que más se ha preocupado por la educación en los medios y desde el British Film Institute se han impartido cursos especializados integrándolos dentro de las materias y como ejes transversales del currículo. En cuanto a los programas televisivos desarrollados para tal fin, habría que destacar el realizado por Andrew Hart en 1991 llamado Understanding the Media, con la colaboración de la cadena pública BBC. Este programa combina la teoría con la práctica y sintetiza las principales aportaciones de los teóricos británicos, en especial, los del investigador y profesor Len Masterman $^{12}$.

En Estados Unidos, un país altamente tecnológico y con una ingente cantidad de estudios realizados sobre efectos de la violencia mediática, se han realizado multitud de

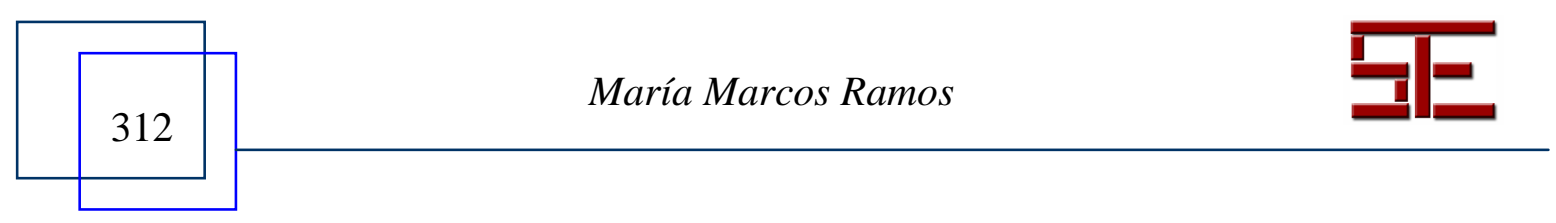




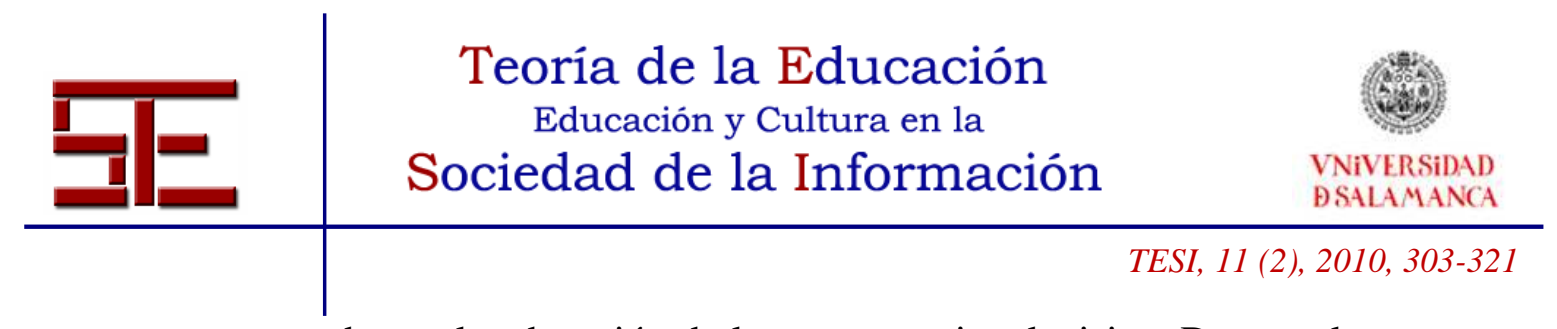

programas centrados en la educación de la competencia televisiva. Dos son los proyectos que mayor repercusión han tenido: el Critical Television Viewing (WNET, 1989) y el Media \& You de Donna Lloyd y Kathleen Tyner (1991).

Preocupados también por desarrollar esta educación audiovisual, en Canadá se han realizado diversos contenidos, La compétence médiatique, desarrollado por Pierre Bélanger y editado por el Ministerio de Educación de Ontario (1989) y el programa Inside the Box de Canadian Broadcasting Corporation. Hay que destacar que han sido los pioneros en el desarrollo de programas de educación del telespectador a través de Internet.

En España han sido muy pocas las acciones que se han llevado a cabo para instaurar una televisión educativa desde que se implantase en España este nuevo medio de comunicación -a finales de los años 50-. Así, la parcela educativa ha sido la más desatendida de todas las facetas llegando a ser inexistente en las televisiones privadas. Son muy pocas las horas de emisión dedicadas al aprendizaje, entendidas como emisiones dedicadas a formar al telespectador, siendo más las horas dedicadas a emisiones culturales, centradas en documentales, concursos, etc. Desde que se creó el Ente Público de Televisión Española, la 2 quedó relegada a espacios culturales y deportivos, siendo minoritarios los espacios puramente educativos. Las cadenas autonómicas que tienen dos canales han seguido la misma estructura que TVE, dedicando su segundo canal a espacios culturales y educativos, siendo los primeros los que mayor presencia acaparan.

Entre las iniciativas llevadas a cabo en España cabe destacar el Convenio firmado en 1992 entre el Ministerio de Educación y Radio Televisión Española para la elaboración del programa La Aventura del Saber ${ }^{13}$. También destacan los proyectos Atenea ${ }^{14}$ y Mercurio $^{15}$ para el desarrollo de los medios audiovisuales en la enseñanza en todo el país. Sin duda, el mayor esfuerzo transnacional que viene realizando el Ministerio de Educación y Cultura desde el comienzo de los noventa en el campo de la televisión educativa es la co-financiación de la Asociación de Televisión Educativa Iberoamericana ${ }^{16}$.

Todas estas administraciones han desarrollado programas educativos realizados por programadores, diseñadores y pedagogos con el único fin de enseñar. Están compuestos, por lo general, de tres elementos: entorno de comunicación o medio en el que se establece el diálogo con el usuario/aprendiz, las bases de datos y los algoritmos que le hacen funcionar. Si los programas educativos están bien diseñados pueden enseñar y contribuir al aprendizaje de una gran variedad de habilidades académicas, transmitir eficazmente conocimientos en diversas materias o promover actitudes, creencias y comportamientos sociales positivos. Así, este tipo de programas educativos pueden fomentar el interés en los libros, la ciencia, la historia, el mundo, etc. Dado que el niño -y el adulto- espera de los medios entretenimiento y no aprendizaje hay que buscar una actitud de activación cognitiva y focalización sobre la tarea de aprender. Hay que buscar en estos programas educativos que no sean vistos como mero entretenimiento sino como una fuente más de aprendizaje.

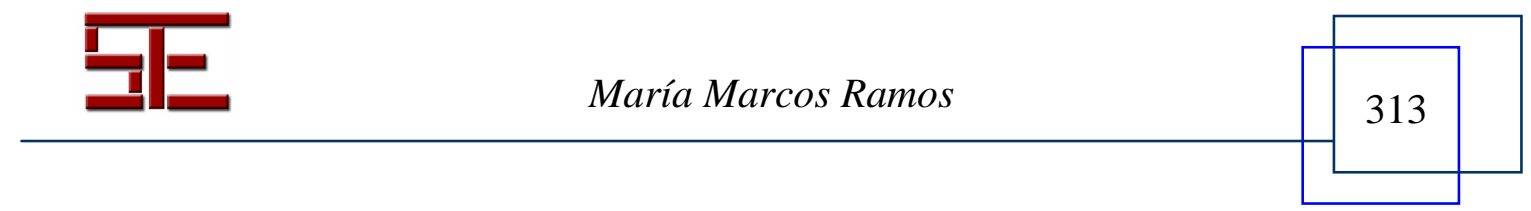




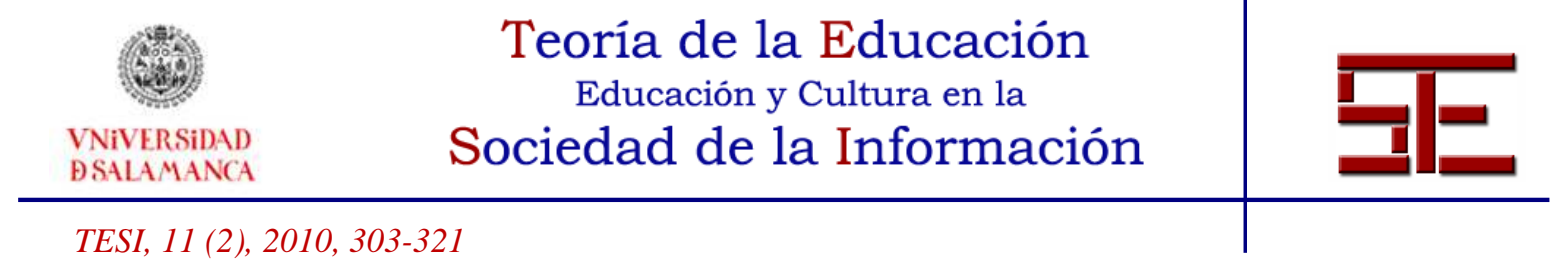

En un estudio, The Early Window Project, del CRITC (Center for Research on the Influences of Television in Children) realizado por Huston, Wright, Marquis y Green en 1999, cuyos resultados han sido publicados en el informe Pigmalión se señala que:

\begin{abstract}
La potencia de la televisión para influir en el éxito escolar, positivamente empleada y con programas educativos de diseño experimental, se confirma tras dos décadas de historia. Pero en este último estudio emerge un nuevo hecho que tiene una gran importancia, tras dos o tres décadas de homogeneización de los marcos escolares de desarrollo entre niñas y niños: la ganancia educativa reflejada era significativa y en la misma dirección para muchachos y muchachas, pero mucho más para los primeros. Un muchacho que de niño había visto 5 horas semanales de programas educativos a los 5 años presentaba una puntuación en resultados escolares un .35 mayor que si no los hubiera visto; pero una muchacha en el mismo caso mostraba un incremento de sólo .10. Por el contrario, la relación negativa con la dieta de programas de entretenimiento de adultos y dibujos animados comerciales cuando tenían 5 años era más marcada en el caso de las muchachas (Del Río, Álvarez y Del Río, 2004).
\end{abstract}

Estos programas educativos pueden ser utilizados tanto por docentes para sus clases diarias como por padres, así como emitidos por televisión. Existe una obligación por parte de las cadenas de televisión de emitir programación infantil y proteger los horarios en los que los niños pueden estar viendo la televisión. Sin embargo, esto es teoría ya que en la práctica apenas se cumple ninguno de los dos preceptos.

En España, los programas educativos suelen ser emitidos a primera hora de la mañana o bien a media mañana -en ambas franjas horarias el target al que van dirigidos debería estar en el colegio-. En consecuencia, la calificación de "educativo" se identifica con programas destinados a un público minoritario y el espacio temporal asignado en la parrilla establece umbrales rígidos de audiencia reducida, con un share de audiencia que no llega generalmente al $10 \%$. Además, no se emiten espacios con un contenido pedagógico ya que bajo el término infantil se admiten todos aquellos contenidos de dibujos animados y/o series juveniles que, en algunos casos, no están destinados a este público $^{17}$. Así, no se cumplen los códigos de regulación impuestos ni se satisface una demanda, la del mercado infantil-familiar con contenidos educativos y pedagógicos. Con este panorama, los niños se ven obligados a ver programación adulta no apropiada para su edad ${ }^{18}$. Por tanto, ya que no existen apenas contenidos educativos destinados al público infantil/juvenil, se deben utilizar los contenidos existentes y trabajar con ellos extrayendo los posibles contenidos educativos, ya sea a través de la contextualización, de la mediación, del debate y análisis crítico, etc. Resulta de vital importancia enfatizar la educación mediática en las escuelas y dar a los alumnos -y a los padres- las claves necesarias cuando vean contenidos no educativos.

García Matilla y sus colaboradores (García Matilla, 1996) proponen en el Informe Marco una clasificación de experiencias educativas realizadas en televisión en España:

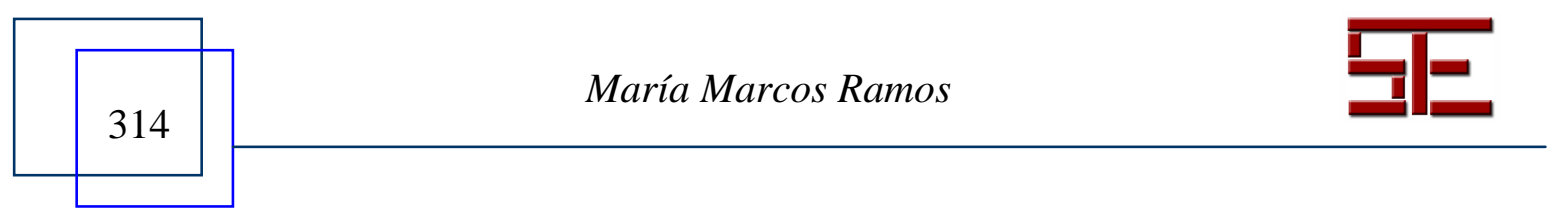




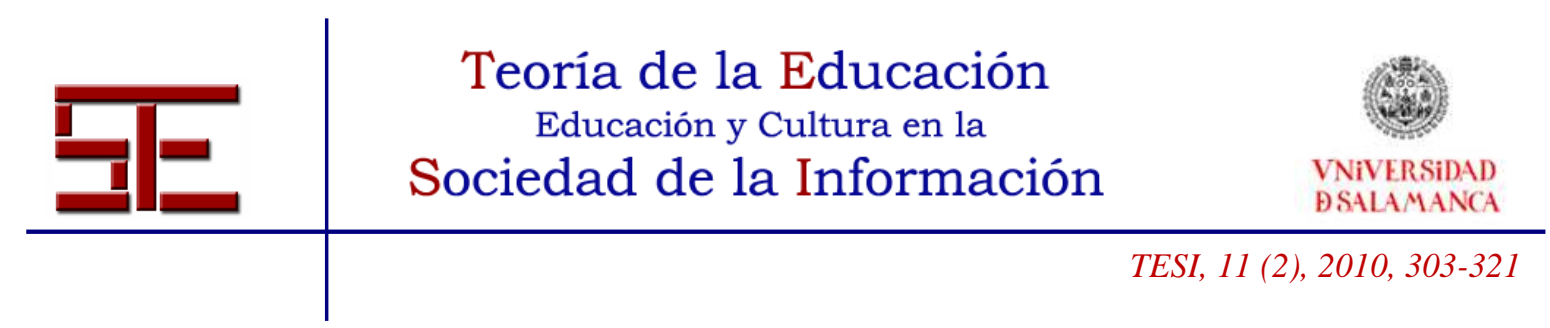

-Experiencias de carácter formal reglado, vinculadas a un currículum académico concreto, con objetivos educativos precisos, con un desarrollo estructurado y progresivo, y que dan acceso a algún título con reconocimiento oficial.

-Otras de carácter formal y no reglado; formal, porque presentan características propias de este tipo de educación: intencionalidad, sistematización, planificación, vinculación con objetivos de algún nivel de la escolaridad, etcétera, y no reglada, porque no se vinculan con la obtención de títulos oficiales.

-Experiencias de carácter no formal o informal, que aprovechando los lenguajes y formatos televisivos incorporan objetivos educativos, generalmente destinados a motivar al público en la adquisición de conocimientos, o se utilizan para el desarrollo de campañas que pretenden el cambio de actitudes, la modificación de hábitos de comportamiento o la prevención de conductas que pueden provocar efectos perniciosos demostrados, ya sea en ámbitos sociales o de carácter más individual. (...)

-Otro grupo de experiencias lo constituyen los programas que no tienen explícitamente intencionalidad educativa, pero que por sus contenidos, o por su pertenencia a determinados géneros y formatos audiovisuales, ejercen, de hecho, una influencia educativa relevante en positivo o en negativo.

En el Informe Pigmalión se recogen una serie de recomendaciones a tener en cuenta por los programadores, señalando que es preciso tener en cuenta tres programaciones culturales:

- En primer lugar, la dieta audiovisual global, lo que podríamos denominar el currículo nacional de un país o una cultura desde el punto de vista del cultivo. Es decir, qué programación u oferta acumulada general, año tras año a lo largo del desarrollo de cada generación, está en el espacio audiovisual general (en la semiosfera de Lotman, o en la iconosfera de Gubern). Hay aquí un espacio prioritario para las políticas culturales nacionales, autonómicas y locales, y para la creación cultural desde un punto de vista de diseño cultural.

- En segundo lugar, es preciso contemplar de manera activa la dieta audiovisual global, entendiéndola como el conjunto formado por iniciativas públicas y privadas de dietas audiovisuales programadas. A las que debe verse constructivamente como un conjunto, potencialmente orquestal (no orquestado) de programas diseñados constructiva y conscientemente a corto, medio y largo plazo, desde la independencia y la responsabilidad. Es importante introducir las ideas de diseño y de creación+investigación formativa, que constituirían una corriente cultural activa, diversa pero coherente, en el escenario audiovisual. El espacio americano en el que se que habla castellano y lenguas latinas próximas configura una semiosfera geocultural muy especial en que podría (y debería) ejercerse esa creación cultural desde el diseño creativo e investigador responsables.

- En tercer lugar, la dieta audiovisual individual, ontogenética, de un niño (muy unida a la de un grupo de hermanos en el contexto familiar). Estamos aquí ante el programa o currículo cultural personalizado. A ella se llega, partiendo de la dieta global, con el juego de factores eco-culturales y familiares. La escuela puede jugar un papel regulador central que hasta ahora, en general, no ha jugado; así como programas especiales transversales (Del Río, Álvarez y Del Río, 2004).

Los mismos autores del informe señalan en sus conclusiones que se hace necesario un plan de acción destinados a reforzar la producción de modelos audiovisuales:

que promuevan el conjunto de factores cuya ausencia repercute en los comportamientos antisociales y violentos: el control de la conducta voluntaria y la disciplina; la empatía, la identificación con

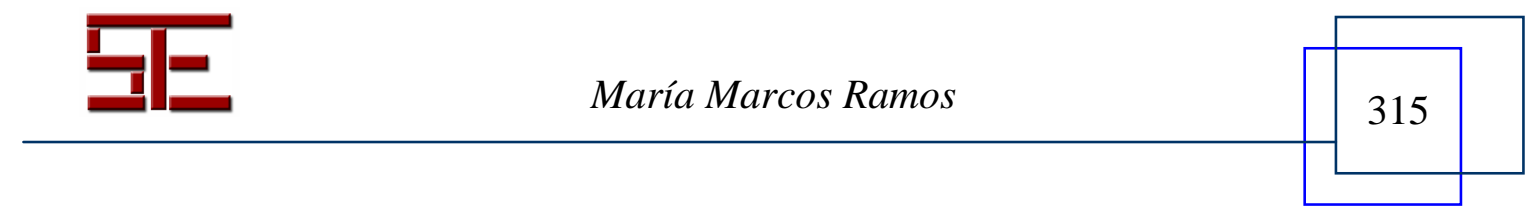




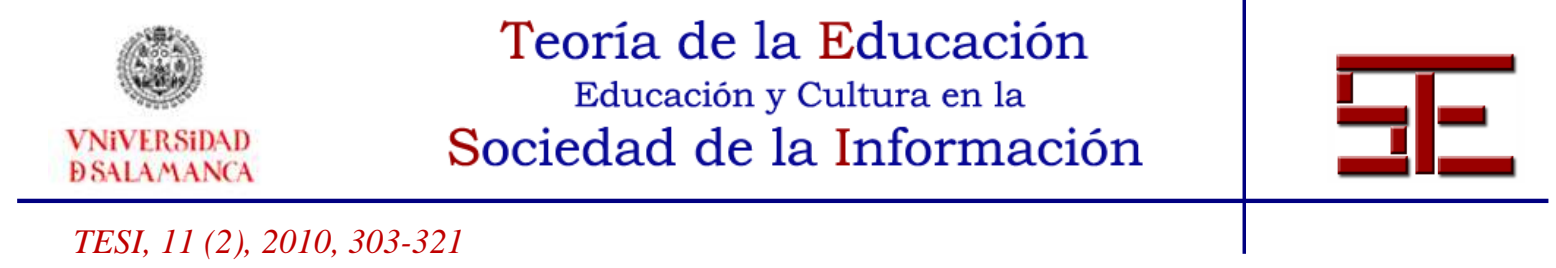

el otro y la resonancia emocional con los demás; la orientación hacia las narrativas y modelos dramáticos prosociales; y las estructuras cognitivas (reglas o modelos) para sustentar el juicio moral (Del Río, Álvarez y Del Río, 2004).

\section{3.- CONCLUSIÓN}

Se ha hace necesario, en la sociedad en la que vivimos, realizar un aprendizaje mediático y que, a ser posible, sea versátil, que nos permita adaptarnos a la sociedad en la que vivimos, una sociedad que no se parece a la que vio crecer a nuestros abuelos, ni siquiera a la de nuestros padres, ni se parecerá a la de nuestros hijos ni, mucho menos, a la de nuestros nietos, ya que, como decía Margaret Mead (1971), "los niños son como emigrantes en el tiempo que, por la fuerza de la mutación cultural, se desarrollan en una cultura distinta a la de sus padres. Los padres tendemos a no tener en cuenta este hecho, tendemos a reestablecer la estabilidad del mundo y a caminar por el vagón y ver caminar a nuestros hijos como si estuviéramos haciéndolo por la plaza de nuestro barrio". Pero no es así, qué duda cabe, el mundo cambia y con él los medios de los que obtenemos información. Así, el contexto de desarrollo de cada generación experimenta cambios culturales transcendentales para su construcción personal. Lo fue para nuestros padres la llegada de la radio y la prensa, lo es para nosotros la televisión, al igual que lo será Internet y las nuevas tecnologías para la generación que nos sigue. Estos cambios afectan en gran medida a la transformación de parte de la cultura situada y a la sustitución de otra parte por una cultura virtual. La rapidez con la que se han sucedido estos cambios en nuestras vidas nos hacen tener que saber adaptarnos rápidamente y nos obligan a vivir en:

Un mundo inestable, un mundo en cambio, donde esas construcciones mediadas se renuevan y ex-
panden con gran rapidez. La proyección de los medios de comunicación y las tecnologías sobre la
vida humana en las tres últimas generaciones ha sido de tal dimensión que la propia teoría de la
mediación cultural debe hacer un esfuerzo para poder seguir su paso. Y aunque esa expansión se
ha producido sobre todo y como decimos, en el espacio virtual de lo deslocalizado, lo ha hecho pa-
radójicamente redefiniendo los propios escenarios locales para hacer un sitio preferente a estos
medios deslocalizados. Colocar los medios en nuestra vida se ha hecho en base a rediseñar los es-
cenarios de la vida cotidiana a su alrededor, desde el salón alrededor del televisor a los escenarios
urbanos de ocio alrededor de videojuegos y audiovisuales (Del Río, Álvarez y del Río, 2004).

En el debate abierto y cada vez más vigente sobre las excelencias y las miserias de los medios de comunicación, del uso de las nuevas tecnologías, la introducción de las TIC en las escuelas, se hace necesario una educación en éstas. Se hace imprescindible en esta nueva sociedad una educación mediática, que vaya más allá de saber leer y escribir:

La tradición educativa ha ligado el dominio de los aspectos centrales de la condición humana (el pensamiento y la apropiación de los sentimientos y contenidos de las identidades culturales o na-

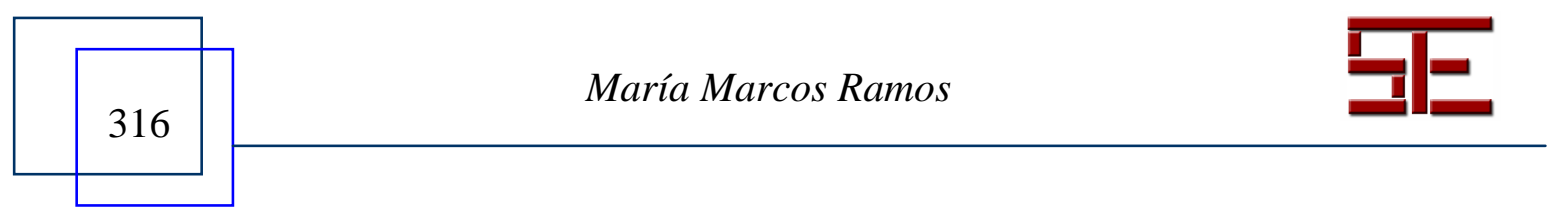




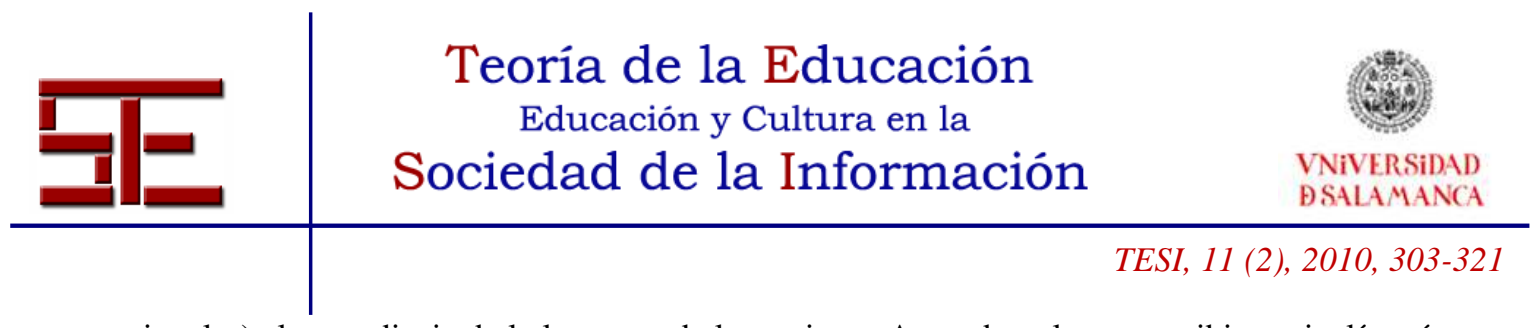

cionales) al aprendizaje de la lectura y de la escritura. Aprender a leer y escribir equivalía así a acceder a una especie de código mágico y universal del pensar y el sentir; a un acervo universal de la ciencia y a otro, más indefinido pero más hondo, de la historia personal y colectiva y del sentimiento y la personalidad, de la propia cultura. (...). En este escenario, las cosas se van a ir complicando en ambas dimensiones. Por una parte, la aparición histórica y el rapidísimo desarrollo de nuevos medios (televisión, redes, ordenador, multimedia), nuevos sistemas simbólicos (informáticos, audiovisuales, ideográficos, etcétera) y la progresiva extensión del plurilingüismo como pauta, hacen que la codificación lectoescrita sea menos simple, menos universal y menos estática. Por otra parte, la batalla por la identidad de las culturas se va a ir polarizando cada vez más hacia el dominio en el mercado de los modelos y repertorios culturales propios y en su apropiación por los ciudadanos, estando estos repertorios escritos en los diversos sistemas simbólicos (alfabéticos, audiovisuales, hipertextuales, etcétera) (Del Río, Álvarez y Del Río, 2004).

Muchos consideran que los medios de comunicación no son objetos de aprendizaje, sino de entretenimiento. Huston, Zillmann y Bryant (1994) señalan que este doble papel de los medios culturales y en concreto de la televisión no se está resolviendo con equilibrio. De este modo, por criterios educativos mostrarían la realidad factual del mundo y un realismo social basado en los modelos de construcción social de acuerdo al mejor diseño del ser humano para la convivencia, esto es, al mejor ser humano posible en el mejor mundo posible. En cuanto al entretenimiento, los medios reflejan una realidad poco real, ya que no se muestra lo real sino lo poco corriente, esto es, un exceso de violencia, conductas amorales... Se debe por tanto romper este dogma y crear contenidos mediáticos que sean capaces de entretener y educar y es en este punto donde se enmarcan las políticas mediáticas educativas, con la creación de contenidos adecuados a la realidad con un fin: educar en y con los medios.

\section{4.- BIBLIOGRAFÍA.}

Aguaded, J. I. (1995). La educación en Medios de Comunicación, más allá de la transversalidad. Comunicar, 4, 111-113.

- (1997). La televisión en el nuevo diseño curricular español. Comunicar, 8, 97110.

- (1999). Convivir con la televisión. Familia, educación y recepción televisiva. Paidós: Barcelona.

- (2001). Nuevas corrientes comunicativas, nuevos escenarios didácticos. Comunicar, 16, 120-130.

- (2005). Enseñar a ver la televisión: una apuesta necesaria y posible. Comunicar, 25, 1, 51-55.

Aguaded, J. I. Y Díaz, R. (2008). La formación de telespectadores críticos en educación secundaria. Revista Latina de Comunicación Social, 63, pp. 121-139. La Laguna (Tenerife): Universidad de La Laguna. Recuperado el 3 de Mayo de 2010, de http://www.ull.es/publicaciones/latina/_2008/12_19_Huelva/Aguaded.html.

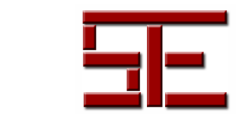

María Marcos Ramos 


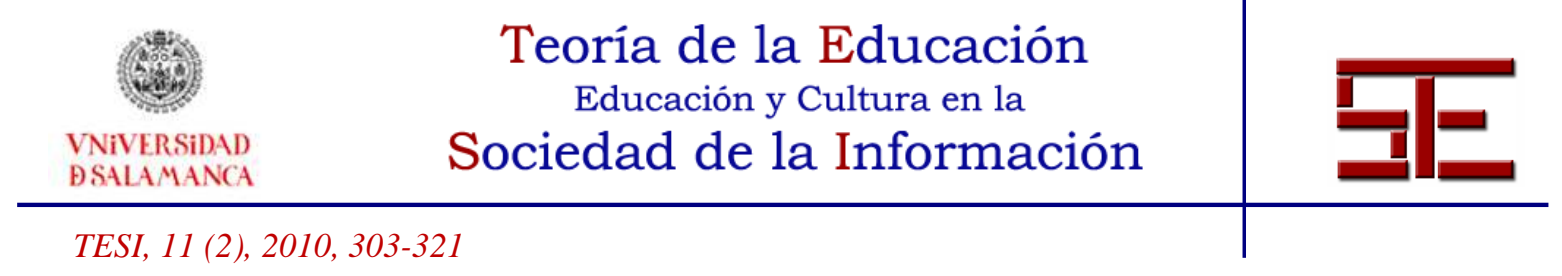

Aguaded, J. I. Y Pérez, A. (1992). Enseñar y aprender con prensa, radio y televisión. Huelva: Grupo Pedagógico Prensa Educación de Andalucía.

Aguaded, M. C. (1995). La influencia de la televisión en nuestros alumnos. Comunicar, 4, $103-105$.

Alonso, M., Matilla, L. Y Vázquez, M. (1995). Teleniños públicos, teleniños privados. Madrid: Ediciones de la Torre.

Ambros A. Y Breu, R (2007). Cine y educación. El cine en el aula de primaria y secundaria. Barcelona: Editorial Grao.

Babin, P. Y Kouloumdjian, M. F. (1983). Les nouveaux modes de comprendre. La génération de l'Audiovisuel et de l'Ordinateur. Lyon: Éditions du Centurión.

Campo-Redondo, M. (2006). El cine como recurso tecnológico en la creación de conocimiento: estudio de caso en la enseñanza de la orientación de la violencia familiar. Enlace, 3, 11-31.

Chalvon, M.; Corset, P. \& Souchon, M. (1982). El niño ante la televisión. Barcelona: Juventud.

De La Torre, S. (1997). Cine formativo. Una estrategia innovadora para los docentes. Barcelona: Ediciones Octaedro.

- (2004). El cine como estrategia didáctica innovadora: metodología de estudio de casos y perfil de estrategias docentes. Contextos Educativos, 6-7, 65-86.

Del Río, P. Y Álvarez, A. (1993). Programas infantiles de televisión: Análisis de líneas actuales y diseño estratégico de alternativas. Informe de investigación no publicado. Madrid: Departamento de Estudios de TVE.

Del Río, P., Álvarez, A., Del Río, M. (2004). Pigmalión. Informe sobre el impacto de la televisión en la infancia. Madrid: Fundación Infancia y Aprendizaje.

Eco, U. (1968). Apocalípticos e integrados. Barcelona: Lumen.

Ferres, J. (1994). Televisión y educación. Barcelona: Editorial Paidós.

García Mantilla, A., Martínez, L. M. Y Rivera, M. J. (1996). La Televisión Educativa en España (Informe Marco). Madrid: MEC.

López, J. A. (1998). Cómo librarse de la tele y sus semejantes. Ayudas para educar con el análisis de contenido. Madrid: Editorial CCS.

MeaD, M. (1971). Cultura y compromiso. Buenos Aires Granica.

Olson, D. (1995). Writing and the mind. En Wertsch, J. V., Del Río, P. \&. Álvarez, A. (Eds.), Sociocultural studies of mind (pp. 95-123). Cambridge, MA.: Cambridge University Press. [Trad. cast.: La escritura y la mente. En, La mente sociocultural (pp. 77-97). Madrid: Fundación Infancia y Aprendizaje.

Pérez, M. A. Y Aguaded, J. I. (1994). Lenguaje y nuevos lenguajes. Comunicar, 2, 33 42.

Pérez Tornero, J. M. (1994). El desafío educativo de la televisión. Para comprender y usar el medio. Barcelona: Paidós Papeles de Comunicación.

- (2003). Libro Blanco: la Educación en el entorno audiovisual, en Quaderns del CAC: Barcelona.

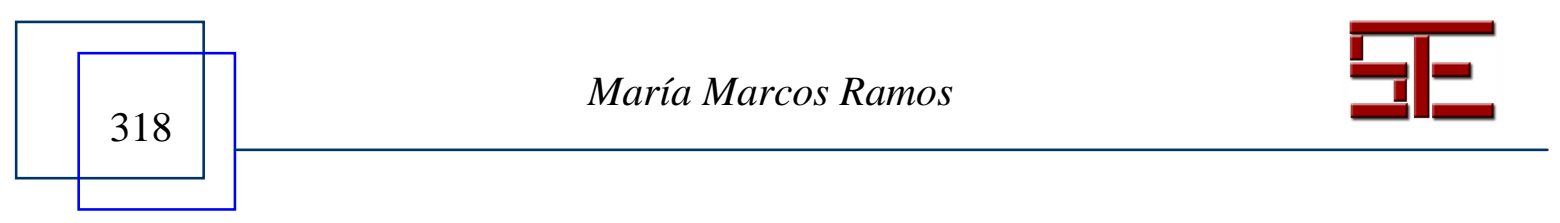




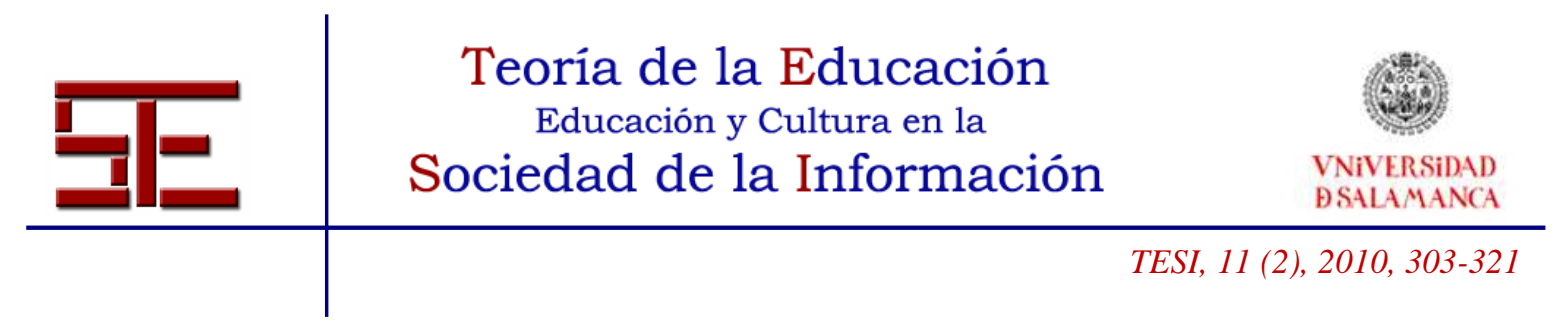

Pérez Tornero, J. M., Llaquet, P., Moyano, M. A., Serrano, M. G., De La Cueva, C., De Diego, I., García Castellano, A. Y Prado, E. (2007). Alternativas a la televisión actual. Barcelona: Gedisa Editorial.

Reyes Torres, M. (1993). La tarea de la Educación para la comunicación. Del otro lado de la imagen. Selección de ponencias presentadas al Séptimo Encuentro "El Universo Audiovisual del Niño Latinoamericano”. La Habana.

Sánchez Noriega, J. L. (1997). Crítica de la seducción mediática. Madrid: Tecnos. - (2007). Los lenguajes de las pantallas: del cine al ordenador. Madrid: MEC.

Tornel, J. L. (2007). Cine formativo mediante enseñanza por tareas: Milagro en Milán, Escuela Abierta, 10, 273-293.

\section{NOTAS}

${ }^{1}$ Con frecuencia, muchos de los autores de textos de psicología y pedagogía ignoran completamente que el niño dedica más horas a ver la televisión que a hablar con sus padres, a jugar, a explorar su entorno físico o dominar la lectura (Singer y Singer, 2001).

${ }^{2}$ En el hogar, la educación visual puede realizarse mediante el uso por parte de los padres de la mediación, además de la visualización de programas educativos.

3 "El aula es un escenario formativo, en el que convergen múltiples actores e indicadores, caracterizado por la complejidad, la interactividad, la inacción, el predominio de la intencionalidad sobre la espontaneidad, la comunicación, la pertenencia... Es el espacio en el que se construyen los conocimientos con mayor facilidad, por cuanto se dan las condiciones adecuadas para transformar la información en formación." (De la Torre, 2004, 67-68).

${ }^{4}$ Umberto Eco ya señaló hace más de tres décadas que "la civilización democrática se salvará únicamente si hace del lenguaje de la imagen una provocación a la reflexión crítica, no una invitación a la hipnosis" (Eco, 1968).

5 "No todos los programas que ve el niño, desgraciadamente, obedecen a un diseño cognitivo estratégico. Y sin embargo, los recursos audiovisuales para focalizar la atención y el procesamiento son mucho más numerosos y poderosos en la representación audiovisual que en la lectoescrita, gracias a las ventajas de modalidades sensoriales sumadas y de sistemas simbólicos combinados de ambas, más el efecto sinérgico que puede lograrse si se combinan de manera integral. Los rasgos visuales (desde la iluminación, el maquillaje, el vestuario, el atrezzo, la puesta en escena) junto a los auditivos y verbales, musicales, además de constituir, como se ha dicho antes, claves de género y formato, pueden emplearse como guías cognitivas del procesamiento y con frecuencia lo son cuando su producción responde a este diseño educativo. Pero es enormemente frecuente que el uso de estos rasgos audiovisuales responda a criterios no estratégicos, sino incidentales y más guiados por tendencias profesionales para atraer más la atención periférica que la estructural” (Del Río, Álvarez, Del Río, 2004).

6 A principios de los años 90 aparece en el Currículo la materia "Comunicación Audiovisual”, con carácter optativo. En 2007, el Real Decreto 1467/2007 define los objetivos, contenidos y criterios de una nueva asignatura, "Cultura audiovisual", que parecía que vendría a sustituir a la anterior. Hoy en día, conviven las dos asignaturas aunque no se ofertan en todos los centros ni para todos los Bachilleratos, sólo en el de Artes.

${ }^{7}$ Es fundamental a la hora de trabajar este aspecto contar con la colaboración de los padres ya que de "ellos dependen en cierta medida los modelos de referencia que los alumnos adquieren e imitan" (Aguaded, 2005, 54).

${ }^{8}$ Hoy en día, este problema de dotación tecnológica está prácticamente solucionado con la implantación en las aulas de la pizarra digital. De esta manera, con un ordenador y con la pizarra digital el aula está dotada tecnológicamente para la reproducción de contenidos audiovisuales.

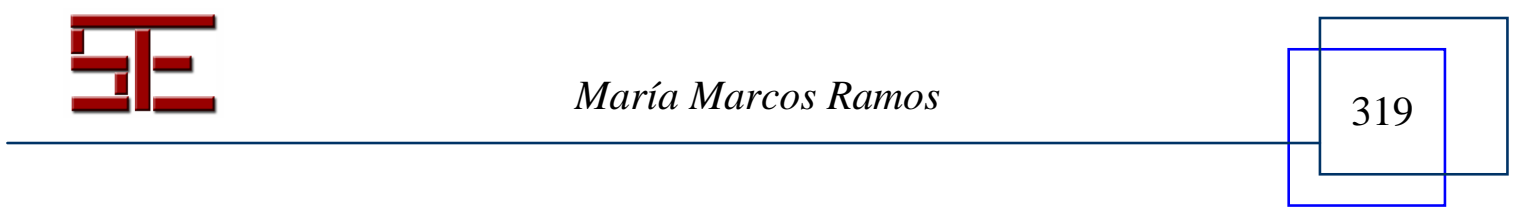




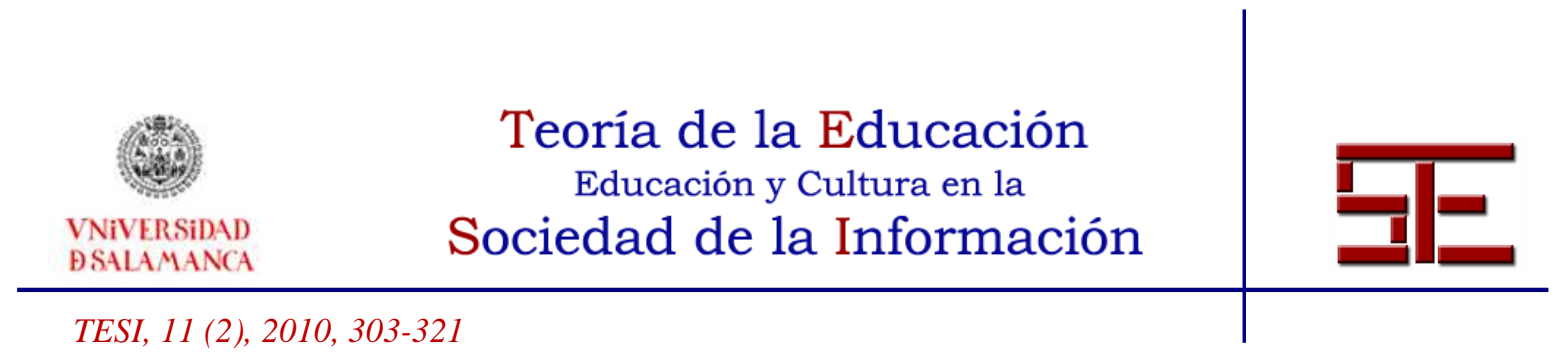

9 Agustín García-Matilla, Luis Miguel Martínez y María José Rivera (1996) clasifican en cuatro los modelos de televisión: experiencias de carácter formal reglado, con objetivos educativos precisos; experiencias de carácter formal no reglado, aunque con intencionalidad, sistematización, planificación y objetivos de algún nivel de escolaridad; experiencias de carácter no formal que, aprovechando los lenguajes y formatos televisivos, incorporan objetivos educativos; y programas que sin tener explícitamente intencionalidad educativa, bien por su contenido, género o formato audiovisual ejercen una influencia educativa relevante.

${ }^{10}$ Los principales canales con programación educativa son: BBC, Arte, Canal Clásico, Canal Historia, Discovery, Documanía, France 5, TV Ontuario, Children TV Workshop, Televisión Educativa de Japón, Hispavision, National Geographic, Natura, Odisea, Rai, Viajar, Teleduc, El club de las ideas, Televisión UNED, Canal 33.

${ }^{11}$ Este programa, financiado por el Ministerio de Educación, promovió la distribución de manuales sobre la educación para los medios de comunicación. Se fomentaban actividades orientadas al alfabetismo mediático crítico como análisis de imagen, lectura crítica, reflexión... Esta campaña implicó a más de 25.000 jóvenes y 3.500 formadores y docentes.

${ }^{12}$ Len Masterman ha sido profesor de Educación Audiovisual en la Universidad de Nottingham (Inglaterra), consultor de la UNESCO y del Consejo de Europa sobre temas de educación audiovisual. Su libro Teaching the Media (La enseñanza de los medios de comunicación) es uno de los referentes sobre la materia.

${ }^{13}$ El espacio de TV Educativa La Aventura del Saber es fruto de un Convenio de Colaboración entre el Ministerio de Educación y Ciencia y Radio Televisión Española. Su programación se ha mantenido ininterrumpidamente desde el año 1992 y su emisión coincide con el calendario escolar, interrumpiéndose durante los períodos vacacionales. El programa dura 60 minutos y se emite de lunes a jueves, entre las 10: 00 y las 11: 00 en el segundo canal, la 2, de Televisión Española.

${ }^{14}$ El proyecto Atenea es un programa de la Consejería de Educación de la Junta de Extremadura que está destinado a los centros de Educación Infantil, Primaria, Educación Especial y Educación de Adultos. Su objetivo es capacitar a grupos de profesores y profesoras en el uso de herramientas que les permitan crear sus propios materiales educativos digitales, así como en el diseño de programas curriculares en los que el uso de las TIC juegue un papel fundamental.

${ }^{15}$ La Junta de Andalucía diseñó en el año 2003 el Proyecto Mercurio para llevar Internet con Banda Ancha a todos los núcleos rurales que, por su escasa población, alejamiento de las capitales o dificultades de acceso, no contarían con esa posibilidad a corto o medio plazo. Además de garantizar el acceso con Banda Ancha en todos los municipios, se pretende fomentar el uso de las Nuevas Tecnologías y potenciar el desarrollo social y económico de las zonas rurales.

${ }^{16}$ La ATEI es la Asociación de las Televisiones Educativas y Culturales Iberoamericanas -refundada con esta denominación en noviembre de 2008-, organización sin ánimo de lucro, creada en 1992 para gestionar la Televisión Educativa y Cultural Iberoamericana - TEIB, Programa de Cooperación de las Cumbres Iberoamericanas de Jefes de Estado y de Gobierno, cuya misión es contribuir al desarrollo de la educación y la cultura en Iberoamérica, mediante el uso de la televisión y otras tecnologías de la información y comunicación. Las emisiones de televisión de la Asociación de Televisión Iberoamericana (ATEI) se inician en 1992 en el marco de las cumbres de Jefes de Estado y de Gobierno de los países iberoamericanos. Su destino son más de 300 instituciones de 23 países, incluidos España y Portugal. Se emite desde España a través del satélite Hispasat. Las principales fuentes de financiación proceden de nuestro país, a través del Ministerio de Educación y Ciencia y de la Agencia de Cooperación Internacional. Las emisiones de la Televisión Educativa Iberoamericana pueden captarse en abierto en España y Portugal vía TV IP si se dispone de una antena parabólica orientada al satélite Hispasat y de un PC con tarjeta descodificadora.

${ }^{17}$ Como ejemplo de esto se podría citar Los Simpsons, que se emiten en la cadena generalista Antena 3 en horario protegido - al mediodía- y dirigido al público infantil cuando la serie de animación no ha sido creada para llegar a este público, sino a un público adulto.

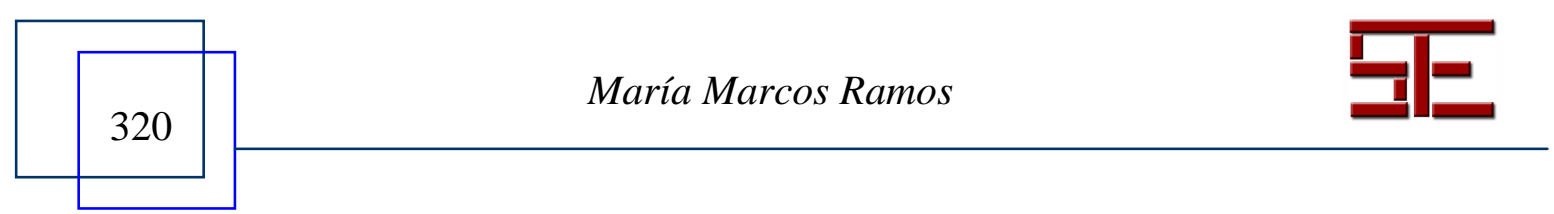




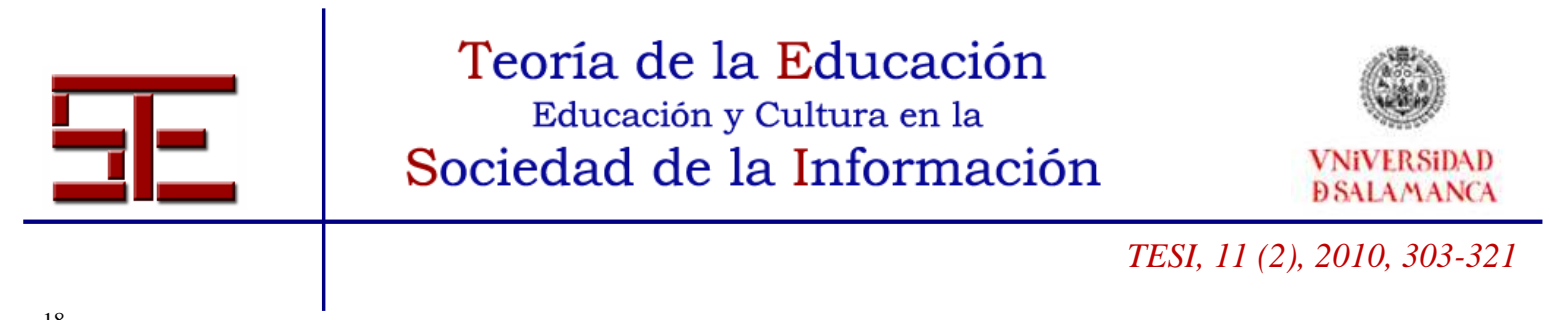

${ }^{18}$ En un estudio sobre la programación infantil de Canal Sur TV, Borrego y de Pablos (1994) señalan la ausencia de programas con objetivos explícitamente formativos o de divulgación dentro de la programación infantil y juvenil.

Para citar el presente artículo puede utilizar la siguiente referencia:

MARCOS RAMOS, M. (2010): Alfabetización mediática. La educación en los medio de comunicación: cine formativo y televisión educativa, en JUANES MÉNDEZ, J. A. (Coord.) Avances tecnológicos digitales en metodologías de innovación docente en el campo de las Ciencias de la Salud en España [monográfico en línea]. Revista Electrónica Teoría de la Educación: Educación y Cultura en la Sociedad de la Información. Vol. 11, $\mathrm{n}^{\circ}$ 2. Universidad de Salamanca, pp. 303-321 [Fecha de consulta: dd/mm/aaaa].

http://campus.usal.es/ revistas_trabajo/index.php/revistatesi/article/view/7081/7114 ISSN: 1138-9737

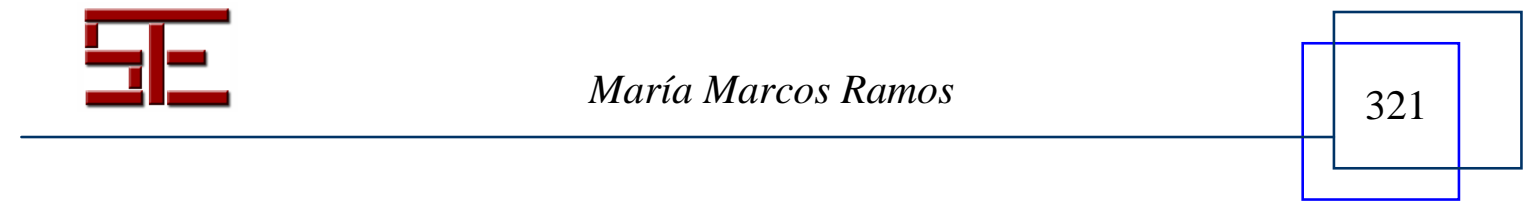

